\title{
Exponential analysis of lobar pressure-volume characteristics
}

\author{
N BEREND, C SKOOG, AND W M THURLBECK \\ From the Department of Pathology, University of Manitoba, Winnipeg, Manitoba, and \\ Department of Pathology, University of British Columbia, British Columbia, Canada
}

\begin{abstract}
In 19 excised left human lungs, seven of which were emphysema-free, lobar pressure-- $\frac{\hat{c}}{\mathrm{~N}}$ volume $(\mathrm{P}-\mathrm{V})$ characteristics were analysed by fitting to the $\mathrm{P}-\mathrm{V}$ data an exponential of the $\mathrm{O}$ form $\mathrm{V}=\mathrm{A}-\mathrm{Be}^{-\mathrm{KPL}}$ (where $\mathrm{V}$ is the volume at a transpulmonary pressure $\left(\mathrm{PL}_{\mathrm{L}}\right.$ ), $\mathrm{A}$ is the theoretical lung volume at infinite $P_{L}, B$ is the difference between $A$ and the intercept of the fitted $\subseteq$ exponential on the volume axis and $K$ is a shape constant). In the emphysema-free lungs there $\overrightarrow{\widehat{D}}$ was no difference in the $\mathrm{B} / \mathrm{A}$ ratio expressed as a percentage, indicating an identical position $\vec{\oplus}$ of the P-V curves of the upper and lower lobes. However the upper lobes had significantly: $(p<0.025)$ higher values for $\mathbf{K}$ than the lower lobes indicating greater compliance. In 10 emphysematous lungs the upper lobes were more severely involved than the lower lobes. In these lungs the difference in $\mathbf{K}$ between upper and lower lobes had been abolished suggesting that the less emphysematous lower lobes had increased compliance relatively more than the upper lobes.
\end{abstract}

Small but definite differences in the pressurevolume $(\mathrm{P}-\mathrm{V})$ characteristics of upper and lower lobes of the lung have been demonstrated in dogs ${ }^{12}$ and rabbits. ${ }^{3}$ However in monkeys the findings were equivocal, depending on whether the volume axis was expressed as percent lobar volume or as $\mathrm{ml} / \mathrm{g}$ of lung tissue. ${ }^{4}$ This was also the case in excised human lungs. ${ }^{5}$ These results demonstrate the problems encountered in expressing the results in a conventional manner-that is, as transpulmonary pressure $\left(\mathrm{PL}_{\mathrm{L}}\right)$ at fixed percentages of lobar volume. Since the volume reached at any given $P_{L}$ is itself dependent on the elastic properties of the lungs, it would be advantageous to express the results in a manner independent of lung volume. Fitting an exponential to the $\mathrm{P}-\mathrm{V}$ data permits quantification of continuously changing compliance in terms of the bulk elastic constant which is independent of lung volume and thus suitable for comparisons of lobar elastic properties. In this study we used an exponential analysis to compare the lobar elastic properties of 19 lungs, seven of which were free of emphysema.

Address for reprint requests: Dr N Berend, Department of Medicine, National Jewish Hospital and Research Center, 3800 East Colfax Avenue, Denver, CO 80206, USA.

\section{Methods}

Left lungs were obtained from 19 subjects who had died suddenly from non-respiratory causes. The lungs were selected for the presence of a complete $\underset{\otimes}{\mathscr{D}}$ interlobar fissure or the absence of interlobar 0 ventilation as previously described in 14 of these 3 . lungs. ${ }^{6}$ The lungs and their individual lobes had $\delta$ more than 20 expiratory $\mathrm{P}-\mathrm{V}$ datum points recorded between a $\mathrm{PL}$ of $30 \mathrm{cmH}_{2} \mathrm{O}(3 \mathrm{kPa})$ and $\mathrm{O}$ $0 \mathrm{cmH}_{2} \mathrm{O}$ by methods described fully elsewhere. ${ }^{B}$

Exponential analysis of the $\mathrm{P}-\mathrm{V}$ data was per-은. formed by a CDC Cyber Model 17 computer to solve the equation $\mathrm{V}=\mathrm{A}-\mathrm{Be}^{-\mathrm{KPL}}$ by an iterative ? least mean squares technique. ${ }^{7} \mathrm{~V}$ is the volume in $\mathrm{N}$ $\mathrm{ml}$ at a pressure $\mathrm{PL}_{\mathrm{L}}$ in $\mathrm{cmH}_{2} \mathrm{O}$. $\mathrm{A}$ is the maximum $\mathrm{N}_{\mathrm{N}}$ theoretical volume at infinite $P_{L}$ and $B$ is the dif- ference in volume between $A$ and the intercept of 0 the fitted exponential on the volume axis. The $\overparen{\Phi}$ continuous change in slope of the $\mathrm{P}-\mathrm{V}$ curve is $\stackrel{\infty}{+}$ quantitated by $\mathrm{K}$ in units $\mathrm{cmH}_{2} \mathrm{O}^{-1}$. The position ${ }^{0}$ of the curve is quantitated by the $\mathrm{B} / \mathrm{A}$ ratio. The goodness of fit of the exponential was quantitated $\cong$ by square of the correlation coefficient $\left(r^{2}\right)$. Using $\stackrel{\mathbb{D}}{\varrho}$ all $\mathrm{P}-\mathrm{V}$ points the curve fit was unsatisfactory since many of the lungs failed the runs test. ${ }^{8} \Omega$ Therefore, successive datum points were deleted 
from Vo (volume at a $\mathrm{PL}$ of $0 \mathrm{cmH}_{2} \mathrm{O}$ ) upwards and the equation resolved using the remaining points until the highest $\mathrm{r}^{2}$ was obtained as described by Colebatch et al. ${ }^{9}$ The lowest volume included in the curve fit with the highest $r^{2}$ was expressed as a percent of the volume at a $\mathrm{PL}$ of $30 \mathrm{cmH}_{2} \mathrm{O}\left(\mathrm{V}_{30}\right)$ and designated Vexp. When fitted to Vexp all curves passed the runs test indicating that there were no runs of data points in excess of those expected by chance on either side of the fitted exponential. The $\mathrm{K}$, Vexp, A, and $\mathrm{B} / \mathrm{A}$ percent of the upper and lower lobes were compared using Student's paired $t$ tests.

The lungs were then inflated with $10 \%$ neutral buffered formalin at a constant PL of $25 \mathrm{cmH}_{2} \mathrm{O}$ $(2.5 \mathrm{kPa})$ for 72 hours. The lungs were sliced and paper-mounted whole lung sections prepared. These were used to grade the degree of emphysema on an arbitrary scale of $0-100 .{ }^{10}$ The bariumimpregnated mid-sagittal slice was examined under water using a dissecting microscope to facilitate detection of very mild degrees of emphysema and was used to modify the score made on the paper sections. Assessment of the presence and severity of emphysema was made without previous know!edge of the $\mathrm{P}-\mathrm{V}$ characteristics of the lobes.

\section{Results}

Seven lungs were emphysema-free (mean age 54 years, range 29 to 86 ). In 12 lungs (mean age 63 years, range 44 to 87 ) emphysema was present (mean emphysema grade 15 , range 5 to 30 ). In the emphysema-free lungs the mean $\mathbf{r}^{2}$ for the whole lungs and upper and lower lobes was 0.9995, 0.9995 , and 0.9994 respectively. This was almost identical to the degree of curve fit achieved with the emphysematous lungs (mean $r^{2} 0.9994$ for the whole lungs and individual lobes).

The mean values for $\mathrm{K}$, Vexp, A, and B/A percent of the emphysema-free lungs are shown in table 1. There were no significant differences for the values of Vexp, A, and B/A percent between the whole lungs and the individual lobes or between the upper and lower lobes. The mean ratio between the upper and lower lobe values of $A$ was $0 \cdot 96$. For $K$ there was a significant difference between the upper and lower lobes $(p<0.025)$ but not between the whole lungs and the individual lobes. The mean ratio of upper and lower lobe $\mathrm{K}$ was 1.04 .

In 10 emphysematous lungs the upper lobes were determined to be more severely involved in the emphysematous process using the grading pictures. Comparison of the results of curve fitting in
Table 1 Exponential constants in the emphysema-free lungs

\begin{tabular}{lccc}
\hline & Whole lung & Left upper lobe & Left lower lobe \\
\hline K & $0 \cdot 202 \pm 0.011$ & $0 \cdot 216 \pm 0.014^{*}$ & $0.208 \pm 0.013$ \\
A & $3499 \pm 252$ & $1988 \pm 193$ & $2060 \pm 94$ \\
B/A $\%$ & $82 \cdot 3 \pm 17 \cdot 5$ & $76.5 \pm 20.8$ & $88 \cdot 5 \pm 22 \cdot 1$ \\
Vesp & $81 \cdot 1 \pm 1 \cdot 3$ & $83.6 \pm 1 \cdot 3$ & $80.9 \pm 1 \cdot 6$ \\
\hline
\end{tabular}

Values are the means $\pm S E$.

* Significantly different from lower lobe (p < 0.025).

$\mathrm{K}=$ shape constant; $\mathrm{A}=$ volume at infinite transpulmonary pressure; $\mathbf{B}=\mathbf{A}$ minus intercept of the fitted exponential on the volume axis; Vexp $=$ volume at which the optimal curve fit occurred expressed as a percent of the volume at a transpulmonary pressure of $30 \mathrm{cmH}_{2} \mathrm{O}$ (3 kPa).

Table 2 Exponential constants in the emphysematous lungs

\begin{tabular}{lccc}
\hline Whole lung & $\begin{array}{l}\text { Upper lobe } \\
\text { (more severe) }\end{array}$ & $\begin{array}{l}\text { Lower lobe } \\
\text { (less severe) }\end{array}$ \\
\hline K & $0 \cdot 187 \pm 0.008$ & $0 \cdot 183 \pm 0.010$ & $0 \cdot 194 \pm 0.006$ \\
A & $3536 \pm 196$ & $2000 \pm 144$ & $2056 \pm 107$ \\
B/A \% & $43.6 \pm 3.6$ & $43.9 \pm 5.9$ & $47.5 \pm 3.7$ \\
Vexp & $79.5 \pm 3.0$ & $86.4 \pm 1.9 *$ & $77.1 \pm 3.1$ \\
\hline
\end{tabular}

For abbreviations see table 1

*Significantly different from lower lobe $(\mathrm{p}<0.01)$.

these emphysematous lungs are shown in table 2 . There was no significant difference in $\mathrm{K}, \mathrm{A}$, or the $B$ /A percent between the more emphysematous upper lobes and the less severely involved lower lobes. The mean ratio of upper and lower lobe $\mathbf{K}$ was 0.94 and the mean ratio of upper and lower lobe $\mathrm{A}$ was 0.97 . However there was a significant difference in Vexp $(p<0.01)$ with Vexp being higher in the more severely involved lobes. This was also true for the two lungs in which the lower lobes were more severely involved. When the exponential was fitted in the more emphysematous lobes over the same range of lung volume as the optimal fit in the less emphysematous lobes, the degree of fit was significantly worse as judged by the $r^{2}(p<0.02 .5)$ in the more emphysematous lobes but this did not affect the results markedly as there was still no significant difference in the values of $K$.

\section{Discussion}

When the lobes of a lung are inflated to a PL of $30 \mathrm{cmH}_{2} \mathrm{O}(3 \mathrm{kPa})$ and one lobe has less recoil than the other, then this lobe would be relatively overdistended. Expressing the $\mathrm{P}-\mathrm{V}$ curve as $\mathrm{PL}_{\mathbf{L}}$ at fixed percentages of $V_{30}$ does not take this into account. We have previously attempted to overcome this problem by measuring the average interalveolar wall distance $(\mathrm{Lm}){ }^{6}$ We demonstrated that the $\mathrm{Lm}$ of the upper and lower lobes inflated 
to a $\mathrm{PL}$ of $25 \mathrm{cmH}_{2} \mathrm{O}(2.5 \mathrm{kPa})$ was identical in emphysema-free lungs and this validated expression of the data as percent $V_{30}$. When expressed in this manner there were no significant differences in $P_{L}$ at any percent of $V_{30}$ between upper and lower lobes although there was a trend for the upper lobe curves to lie to the left of the lower lobe curves. However our determination of Lm may not be sufficiently sensitive to detect slight overdistension.

The exponential analysis of $\mathrm{P}-\mathrm{V}$ data permits quantification of both position of the curve and its shape. The value of $K$, the shape constant, is independent of lung volume and this overcomes the problems described above. In the emphysema-free lungs the values of $K$ obtained from the upper lobes were slightly but significantly greater than those from the lower lobes. Since the value of $K$ is directly proportional to lung compliance, this implies that upper lobe compliance is greater than that of the lower lobe. There was a trend for B/A percent to be lower in the upper lobes indicating a shift to the left of the P-V curves relative to the lower lobes but this was not statistically significant. However it should be noted that the exponential fit was only performed over a small range of lung deflation since data points below Vexp were edited out. This was necessary because we have shown that if the exponential fit is performed at lower lung volumes the resulting $\mathrm{r}^{2}$ is age dependent and the curve-fit does not pass the runs test. Furthermore in old excised lungs the values of $K$ and $r^{2}$ are heavily dependent on the volume range over which the curve-fit is carried out. We therefore rigorously ensure that the values of $\mathrm{K}$ are only compared in lungs or lobes that have an equivalent "goodness of fit" of the exponential.

In the emphysematous lungs in which the upper lobes were more severely involved there were no significant differences in lobar $\mathrm{K}, \mathrm{A}$, or the $\mathrm{B} / \mathrm{A}$ percent. It is of interest that the ratio of upper to lower lobe $\mathrm{K}$ in the emphysematous lungs was less than unity in contrast to the pattern in the emphysema-free lungs. This implies that either $\mathbf{K}$ in the less severely involved lower lobes increased more relative to the upper lobe or that $K$ in the more severely involved upper lobe decreased more relative to the lower lobe. Since the degrees of emphysema in the emphysematous lungs were so mild in this study and the values of $K$ between the emphysematous and emphysema-free lungs so close it is not possible to separate these two possibilities. However these findings are consistent with the concept $^{11}$ that loss of elastic recoil in emphysema is not attributable directly to the presence of em- physematous spaces but rather to a diffuse effect on scleroproteins throughout the lung. Since centrilobular emphysematous spaces have been shown to be stiffer than the surrounding lung, ${ }^{12}$ one may expect $K$ in the less severely involved part of the lung to increase more.

The finding that Vexp in the more severely involved lobes was significantly greater than in the less severely involved lobes implies that with greater degrees of emphysema the lungs deflate exponentially over a smaller volume range. We have also shown this to be the case when comparing whole emphysematous and emphysema-free lungs (unpublished observation).

The values of $\mathrm{K}$ for the whole emphysematous lungs were slightly but not significantly lower than those for the whole emphysema-free lungs. We have found that $K$ is so variable that it will not always distinguish between the presence and absence of emphysema (unpublished observation). Thus our observation that early emphyesma (the emphysema in all the lungs of this study was mild) does not always result in increased values of $K$ is at variance with the findings of Colebatch and co-workers, ${ }^{13} 14$ our group of emphysematous lungs having lower values of $\mathbf{K}$ despite the presence of mild emphysema.

This work was supported by Medical Research Council (Canada) Grant no MA6179 and grants from the Royal Australasian College of Physicians and the Coppleson Postgraduate Medical Institute of the University of Sydney, NSW, Australia. NB was a Fellow of the MRC, Canada.

\section{References}

1 Frank NR. A comparison of static volume- 윽 pressure relations of excised pulmonary lobes of $\supset$ dogs. J Appl Physiol 1963; 18:274-8.

2 Faridy EE, Kidd R, Milic-Emili J. Topographical distribution of inspired gas in excised lobes of $\sigma$ dogs. J Appl Physol 1967; 22:760-6.

3 D'Angelo E. Local alveolar size and transpulmonary pressure in situ and in isolated lungs. Respir Physiol 1972; 14:251-66.

4 Paré PD, Boucher R, Michaud MD, Hogg JC. Static lung mechanics of intact and excised monkey lungs and lobes. J Appl Physiol 1978; 44:54752.

5 Silvers GW, Petty TL, Stanford RE, Filley GW. The elastic properties of lobes of excised human lungs. Am Rev Respir Dis 1979; 120:207-9.

6 Berend N, Skoog C, Thurlbeck WM. Lobar pressure-volume characteristics of excised human lungs. Thorax 1981; 36:290-5.

7 Glaister DH, Schroter RC, Sudlow MF, Milic年 
Emili J. Bulk elastic properties of excised lungs and the effect of a transpulmonary pressure gradient. Respir Physiol 1973; 17:347-64.

8 Gibson GJ, Pride NB, Davis J, Schroter RC. Exponential description of the static pressure-volume curve of normal and diseased lungs. Am Rev Respir Dis 1979; 120:799-811.

9 Colebatch HJH, Ng CKY, Nikov N. Use of an exponential function for elastic recoil. J Appl Physiol 1979; 46:387-93.

10 Thurlbeck WM, Dunnill MS, Hartung W, Heard BE, Heppleston AG, Ryder RC. A comparison of three methods of measuring emphysema. Hum Pathol 1970; 1:215-26.
11 Thurlbeck WM. Aspects of chronic airflow obstruction. Chest 1977; 72:341-9.

12 Hogg JC, Nepszy SJ, Macklem PT, Thurlbeck WM. Elastic properties of the centrilobular emphysematous space. J Clin Invest 1969; 48: 1306-12.

13 Colebatch HJH, Ng CKY, Nikov N. A single exponential to express the changes in the shape of elastic recoil with age and emphysema. Aust $N Z$ J Med 1977; 7:668-9.

14 Greaves IA, Colebatch HJH. Elastic behavior and structure of normal and emphysematous lungs post mortem. Am Rev Respir Dis 1980; 121: $127-36$. 